Check for updates

Cite this: RSC Adv., 2018, 8, 31358

Received 14th July 2018

Accepted 24th August 2018

DOI: $10.1039 / c 8 r a 05999 c$

rsc.li/rsc-advances

\section{Extracellular probiotic lipase capped silver nanoparticles as highly efficient broad spectrum antimicrobial agents $\dagger$}

\author{
Imran Khan, $\ddagger^{\mathrm{a}}$ Nivetha Sivasankaran,,$^{\mathrm{a}}$ Ravikiran Nagarjuna, \\ Ramakrishnan Ganesan (iD *b and Jayati Ray Dutta*a
}

\begin{abstract}
The microbial resistance to different drugs due to excessive usage of antibiotics in various domains has become a serious environmental threat in recent years. This gave the impetus to researchers to find alternatives that do not lead to multi-drug resistant microbes. In this backdrop, silver nanoparticles (Ag NPs) have become a popular choice due to their potential broad spectrum of antimicrobial attributes. Recent literature caution that about 400 metric tons of Ag NPs are synthesized annually all over the world that could cause environmental hazards when used at higher concentrations than the toxicity limit. However, most of the literature reports use higher concentrations of Ag NPs and exposure to such concentrations may lead to environmental and health hazards. In this study, a series of Ag NPs have been synthesized using a lipase derived from a probiotic source Lactobacillus plantarum as the stabilizing agent. The Ag NPs synthesized through different combinations of lipase and $\mathrm{AgNO}_{3}$ are characterized using various techniques such as UV-visible spectroscopy, FT-IR, ED-XRF, DLS and HRTEM. The lipase capped Ag NPs have been studied for their antimicrobial activity against representative microbes such as Pseudomonas putida, Staphylococcus aureus and Aspergillus niger. Our initial results reveal that the lipase capped Ag NPs possess high potential towards broad spectrum antimicrobial applications at concentrations much lower than the toxicity limit of the standard model, zebra fish.
\end{abstract}

\section{Introduction}

Many ancient cultures have used several antimicrobial compounds based on selected plant materials, colloidal metals and specific mold extracts to treat infections. ${ }^{1}$ These natural extracts and colloidal metals were replaced by the discovery of synthetic antibiotics in the early $20^{\text {th }}$ century. Since their discovery and commercial use, these antibiotics have saved innumerable lives. ${ }^{2}$ In the early 1940 s, the antibiotic penicillin was prescribed to control serious bacterial infections among World War II soldiers. ${ }^{3}$ Ever since, antibiotics have played a major role in treating infections in cancer or immune compromised patients, diabetics, organ transplants, joint replacements, cardiac surgeries and thereby increasing life spans across the world. ${ }^{4}$ Their use is not limited to humans, and

${ }^{a}$ Department of Biological Sciences, BITS Pilani, Hyderabad Campus, Jawahar Nagar, Kapra Mandal, Hyderabad - 500078, Telangana, India. E-mail: jayati@hyderabad. bits-pilani.ac.in; Tel: +91406630 3542

${ }^{b}$ Department of Chemistry, BITS Pilani, Hyderabad Campus, Jawahar Nagar, Kapra Mandal, Hyderabad -500078, Telangana, India.E-mail: ram.ganesan@hyderabad. bits-pilani.ac.in; Tel: +914066303602

$\dagger$ Electronic supplementary information (ESI) available. See DOI: 10.1039/c8ra05999c

\$ Both authors contributed equally. have also been employed in bee-keeping, growth promoters in animal husbandry, horticulture, fish farming, food preservation and antifouling paints. ${ }^{5}$ The use of antibiotics across various domains even at a low-concentration exposure to microbes results in selection and spread of antibiotic-resistant strains. ${ }^{6}$

Apart from this, over prescription and misuse of antibiotics conferred resistance to clinically useful antibiotics as well. This is a threat to human healthcare system and therefore warrants key measures to tackle the risks posed by microbial resistance to antibiotics. $^{7}$ This rise in resistance of microbial organisms to various antibiotics in turn results in increasing the cost of health care. Thus, the need of the hour is to engage in developing effective and stable antimicrobial agents that are alternatives to antibiotics for combating microbial resistance. This has initiated the quest for new antimicrobial drugs that possess structures not related to the current active pharmaceutical ingredients in biological and medicinal chemistry.

Silver nanoparticles (Ag NPs), on the other hand, have become the popular choice recently for antimicrobial properties in several applications including food storage containers, cosmetics, wound healing dressings etc. ${ }^{8}$ It is reported that around 400 metric tons of Ag NPs have been produced annually. ${ }^{9}$ Several reports exist on antimicrobial activity of Ag NPs due to the advantage that the microbes do not develop 
resistance against them easily, when compared to the antibiotics where they eventually develop resistance through genetic mutations. ${ }^{10}$ Although Ag NPs can act alone as anti-bacterial agent, their aggregation in the absence of appropriate capping agents severely inhibits the antimicrobial action. ${ }^{11}$ This can be overcome by employing an appropriate capping agent onto the $\mathrm{Ag}$ NPs. A variety of synthetic polymers, natural polymers, biomacromolecules and surfactants such as poly-( $N$-vinyl-2pyrrolidone) (PVP), polyethylene glycol (PEG), polyvinyl alcohol (PVA), starch, cellulose, sodium dodecyl sulfate (SDS), citrate, bovine serum albumin (BSA), fungal and plant protein extracts have been employed as capping agents for Ag NPs. ${ }^{\mathbf{1 2 - 1 7}}$ Among such various capping agents, bio-derived molecules such as enzymes, saccharides and plant derived molecules are considered to be more eco-friendly and bio-compatible. Proteinaceous capping agents have additional advantage of being amphoteric in nature, which could enable the interaction of the capping agent with poly cationic and poly anionic moieties present on the bacterial surface..$^{18,19}$

Despite the large scale industrial applications of Ag NPs, their utility also comes with a cost. Their excessive usage in the recent years has raised significant concerns among the researchers working in the field of environmental toxicology. While the permissible exposure limit set by Occupational Safety and Health Administration for soluble silver is $0.01 \mathrm{mg} \mathrm{m}^{-3}$, the literature reports indicate the lethal dose $50\left(\mathrm{LC}_{50}\right)$ of $\mathrm{Ag}$ NPs ( $\sim 80 \mathrm{~nm}$ in diameter) in zebra fish model is about $84 \mathrm{ng} \mathrm{mL}{ }^{-1}$, which is in the ppb concentration scale. ${ }^{\mathbf{2 0 , 2 1}}$ However, except a very few articles, majority of the studies reported in the literature used the concentration of Ag NPs in ppm scale. Thus, while in the process of addressing antimicrobial resistance caused by antibiotics, the excess of Ag NPs released in the environment could result in a secondary health hazard and environmental threat. Furthermore, the Ag NPs are shown to affect the ammonia-oxidizing bacteria in biological nutrient removal and waste water treatment. ${ }^{22}$ Therefore, it is imperative that the concentration of Ag NPs released in the environment should be very much in the acceptable level. In the present study, Ag NPs capped with lipase from probiotic source of Lactobacillus plantarum have been synthesized and studied for their antimicrobial properties against Pseudomonas putida, Staphylococcus aureus and Aspergillus niger. ${ }^{23}$ Although lipases are present in various fungal and bacterial sources, Lactobacillus plantarum is preferable as they are probiotics and part of the human mucosal surface microflora. Due to this reason, they are known to be highly biocompatible. Recently, we have shown that $\mathrm{Au}$ nanoparticles capped with Lactobacillus plantarum lipase are hemocompatible. ${ }^{24}$ Furthermore, it has also been shown that the functional groups such as $-\mathrm{COOH}$ present in the proteins are useful in chemically anchoring the nanoparticles onto $\mathrm{Fe}_{3} \mathrm{O}_{4}$ to facilitate facile magnetic recoverability and thereby minimizing the threat of releasing into the aquatic environment. $^{25}$ Therefore, we have studied the minimum inhibitory concentration (MIC) of the lipase capped Ag NPs against the microbial strains in the concentration range well below the $\mathrm{LC}_{50}$ values for zebra fish as a step toward absolute eco-friendly and biocompatible antimicrobial agent. ${ }^{21}$

\section{Materials and methods}

\subsection{Materials}

Lipase from Lactobacillus plantarum (MTCC 4461) was isolated as per our previous reports. ${ }^{26,27}$ Silver Nitrate, $\mathrm{NaBH}_{4}$ and PBS buffer ( $\mathrm{pH}$ 7.4) used were purchased from Sigma Aldrich. Pseudomonas putida, Staphylococcus aureus and Aspergillus niger culture were obtained from MTCC, Chandigarh, India.

\subsection{Preparation of lipase-capped silver nanoparticles (Ag NPs)}

About $0.2,0.6$ and $1.0 \mathrm{mM}$ concentrations of silver nitrate solutions were freshly prepared in deionized water and used for the nanoparticles synthesis within $2 \mathrm{~h}$ of time. To $1 \mathrm{~mL}$ of the above mentioned silver nitrate solutions, $0.5 \mathrm{~mL}$ of lipase isolated from Lactobacillus plantarum was added such that the final lipase concentrations for each concentration of silver nitrate solution was 25,50 and $100 \mu \mathrm{g} \mathrm{mL} \mathrm{m}^{-1}$. Finally, the reduction of silver nitrate was accomplished by adding 1.05 to 1.1 equivalent of sodium borohydride with respect to silver nitrate. The slight excess of sodium borohydride was to ensure complete reduction of $\mathrm{Ag}^{+}$ions.

\subsection{Characterization of lipase-capped Ag NPs}

The formation Ag NPs capped with different concentrations of lipase was followed using UV-visible spectrophotometer (Shimadzu UV-3600 plus). Energy dispersive X-ray fluorescence (EDXRF) studies were performed using Epsilon-1 Analytical instrument to ascertain the chemical identity of silver. Fourier Transform infrared (FT-IR) analyses of the synthesized Ag NPs were performed using Shimadzu 8400S spectrophotometer to confirm the lipase capping. Malvern Zeta Sizer Nano instrument was used to characterize the lipase capped Ag NPs to determine the hydrodynamic diameter. The morphological characteristics were analyzed using high-resolution transmission electron microscopy (HR-TEM, FEI, Tecnai G2, F30). For this, $\sim 10 \mu \mathrm{L}$ of the lipase capped Ag NPs solution was dropped over the TEM grids and dried in a vacuum desiccator for overnight.

\subsection{Evaluation of antimicrobial activity of the lipase capped Ag NPs on Pseudomonas putida}

The Pseudomonas putida was cultured for 12 hours at $37{ }^{\circ} \mathrm{C}$ under shaking conditions (150 rpm) in Luria Bertani (LB) broth medium. To find the minimum inhibitory concentration (MIC), the initial cell concentration of $2.3 \times 10^{5}$ colony forming units per $\mathrm{mL}$ (CFU $\mathrm{mL}^{-1}$ ) culture was taken and treated individually with 10, 15, 20, 25 and $30 \mathrm{nM}$ concentrations of the sample solution containing $\mathrm{Ag}$ NPs with three different concentrations of $0.2,0.6$ and $1.0 \mathrm{mM}$ (with respect to elemental $\mathrm{Ag}$ ) each separately capped with 25,50 and $100 \mu \mathrm{g} \mathrm{mL}^{-1}$ of lipase. This culture mixed with $\mathrm{Ag}$ NPs was then incubated at $37{ }^{\circ} \mathrm{C}$ under shaking conditions (100 rpm) for 6 hours in dark. The positive control was the culture treated with $10 \mu \mathrm{g} \mathrm{mL} \mathrm{m}^{-1}$ of ampicillin. The negative controls were the cultures treated separately with pristine lipase and $\mathrm{NaBH}_{4}(\mathrm{SB})$. The conditions for the positive 
and negative control were same as that of the former. The growth was recorded in terms of optical density at $600 \mathrm{~nm}$ using UV-Vis spectrophotometer after 6 hours of incubation. MIC was deduced by counting the CFUs to study the effect of lipase capped silver nanoparticles as compared to that of positive and negative controls. All the antimicrobial studies were performed in triplicates.

\subsection{Evaluation of antimicrobial activity of the lipase capped Ag NPs on Staphylococcus aureus}

The $S$. aureus was cultured for 24 hours at $37^{\circ} \mathrm{C}$ under shaking conditions ( $150 \mathrm{rpm}$ ) in LB broth medium. About $2.8 \times 10^{5} \mathrm{CFU}$ $\mathrm{mL}^{-1}$ was taken and treated with the nanoparticles in a similar fashion that of $P$. putida and the optical density at $600 \mathrm{~nm}$ was recorded using UV-Vis spectrophotometer after 6 hours of incubation with nanoparticles. MIC was deduced to study the effect of lipase capped Ag NPs as compared to that of positive and negative controls.

\subsection{Evaluation of antimicrobial activity of the lipase capped Ag NPs on Aspergillus niger}

The Aspergillus niger spores were inoculated in a media containing $8.76 \mathrm{mM}$ of sucrose, $2.35 \mathrm{mM}$ of sodium nitrate, $0.734 \mathrm{mM}$ of potassium dihydrogen phosphate, $0.41 \mathrm{mM}$ of magnesium sulphate, $0.067 \mathrm{mM}$ of potassium chloride and $0.658 \mathrm{mM}$ of ferrous sulfate. The culture was incubated at $28{ }^{\circ} \mathrm{C}$ for 48 hours to reach the $\log$ phase. About $1 \mathrm{~g}$ of the biomass of fungi for control and sample grown after 48 hours of incubation was treated with 10, 15, 20, 25 and $30 \mathrm{nM} \mathrm{Ag}$ NPs separately in a similar fashion to $P$. putida. The cultures were incubated for 6 hours at $28{ }^{\circ} \mathrm{C}$ in dark condition and the dry weights of the treated biomasses were determined after drying in hot air oven at $60{ }^{\circ} \mathrm{C}$ for $15-20$ minutes. The positive control was the culture treated with $10 \mu \mathrm{g} \mathrm{mL} \mathrm{m}^{-1}$ of amphotericin B. From the bar graphs of dry weight of biomass versus concentration, the MIC values were obtained.

\section{Results \& discussion}

The pictorial representation of the lipase capped Ag NPs is shown in Scheme 1. The synthesized lipase capped Ag NPs were initially characterized using UV-Vis spectrophotometer and the results are presented in Fig. 1(a-c). In all the three concentrations of $\mathrm{AgNO}_{3}$ such as $0.2,0.6$ and $1.0 \mathrm{mM}$, the formation of strong plasmonic peaks in the range of $400-420 \mathrm{~nm}$ clearly indicated the successful synthesis of Ag NPs. ${ }^{28}$ Interestingly, at a fixed concentration of $\mathrm{AgNO}_{3}$, there is a trend of increasing plasmonic peak intensity with increasing the concentration of lipase capping agent. This is indicative of formation of smaller size and in turn larger number of Ag NPs with the systematic increase in lipase concentration. Furthermore, with the systematic increase in the concentration of $\mathrm{AgNO}_{3}$, the absolute absorbance values of the plasmonic peaks were found to increase linearly, thus confirming the quantitative conversion of the starting materials into lipase capped Ag NPs. To verify the presence of any unbound proteins, we performed SDS-PAGE studies on 25, 50 and $100 \mu \mathrm{g} \mathrm{mL}^{-1}$ lipase capped Ag NPs synthesized from $1.0 \mathrm{mM}$ of $\mathrm{AgNO}_{3}$ solution and the results are presented in Fig. S1.† It can be seen from the figure that the pristine lipase possessed a molecular weight of $\sim 66 \mathrm{kDa}$. However, the 25, 50 and $100 \mu \mathrm{g} \mathrm{mL}{ }^{-1}$ lipase capped $\mathrm{Ag}$ NPs samples migrated close to $97 \mathrm{kDa}$ from their initial positions under identical experimental conditions. This could be due to the very high molecular weight of Ag NPs that are capped with lipase. Furthermore, no other band against the pristine lipase or any other position was observed, indicating the absence of any excess of lipase.

The chemical identity of the nanoparticles was further ascertained using a powerful technique, energy dispersive X-ray fluorescence (ED-XRF) over the Ag NPs solutions synthesized from 0.2, 0.6 and $1 \mathrm{mM} \mathrm{AgNO}{ }_{3}$ solutions capped with $100 \mu \mathrm{g}$ $\mathrm{mL}^{-1}$ of lipase (Fig. 1(d)). It can be seen from the figure that the characteristic $\mathrm{Ag} \mathrm{L}_{\alpha}, \mathrm{Ag} \mathrm{L}_{\beta 1}$ and $\mathrm{Ag} \mathrm{L}_{\beta 2}$ peaks were observed at $2.98,3.17$ and $3.68 \mathrm{keV}$, respectively, which corroborates the chemical identity of silver. In addition, a gentle increase in the peak intensity with increasing the concentration of silver additionally corroborates the observation from UV-Vis spectroscopy studies.

Fourier Transform infrared (FT-IR) analyses were performed in order to verify the capping of lipase over Ag NPs. Three samples such as pristine Ag NPs (reduced with $\mathrm{NaBH}_{4}$ in the absence of any capping agent), pristine lipase and Ag NPs synthesized in the presence of $100 \mu \mathrm{g} \mathrm{mL}^{-1}$ of lipase were

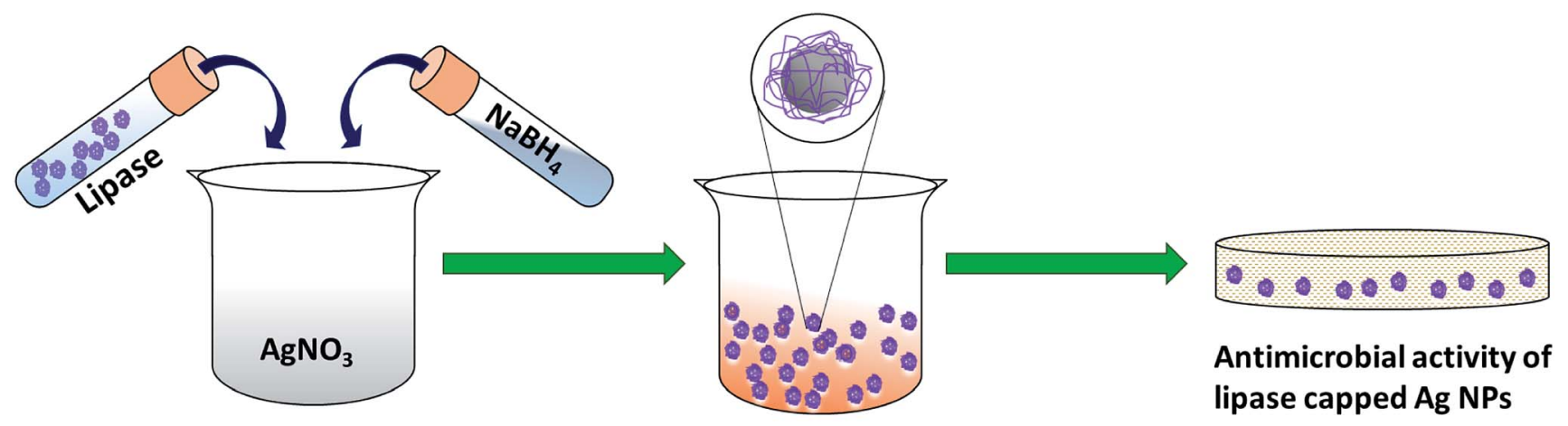

Lipase capped Ag NPs

Scheme 1 Pictorial representation of the synthesis of lipase-capped Ag NPs for antimicrobial activity. 

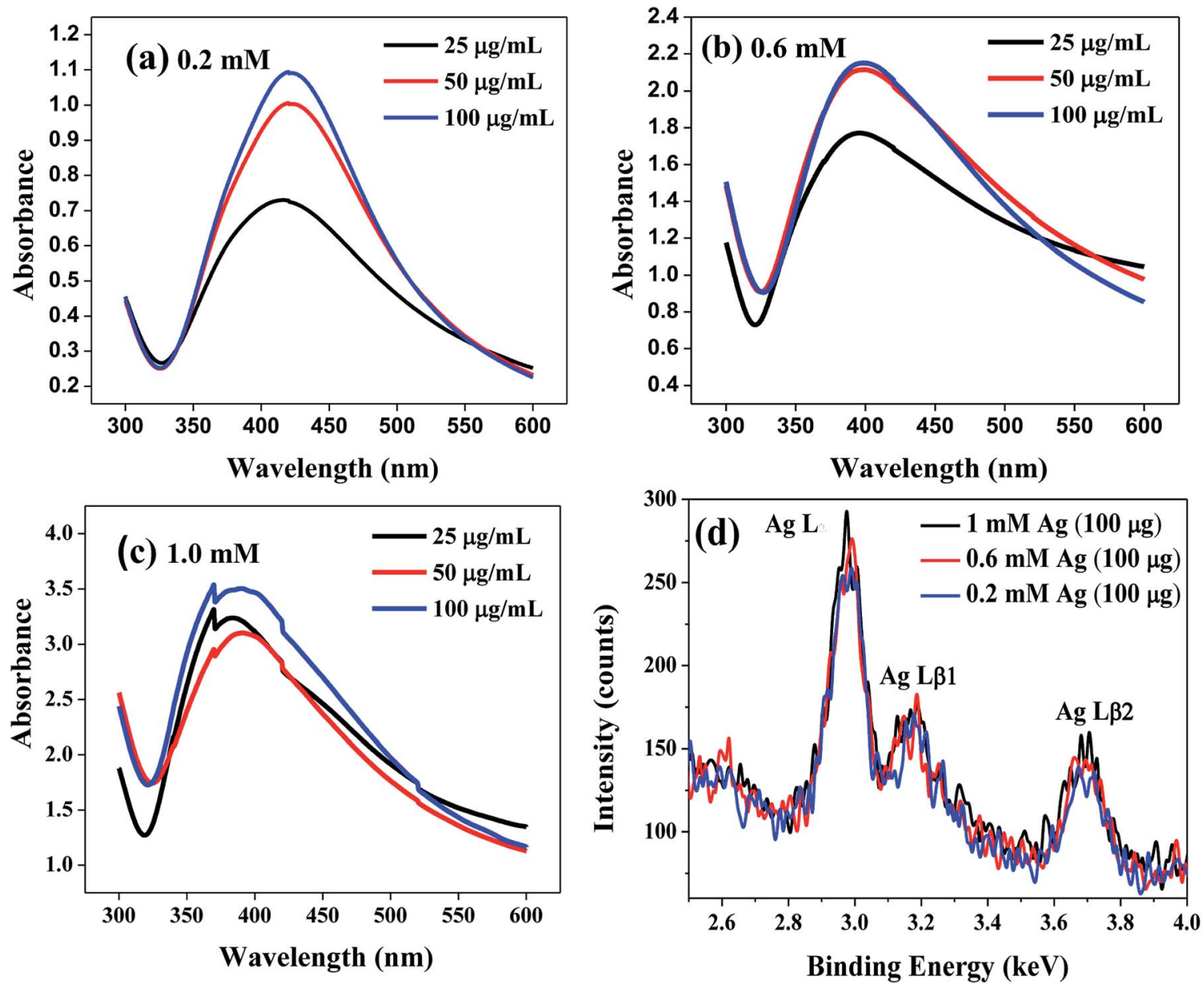

Fig. 1 UV-Vis absorption spectra of Ag NPs synthesized from (a) $0.2 \mathrm{mM}$, (b) $0.6 \mathrm{mM}$ and (c) $1.0 \mathrm{mM} \mathrm{AgNO}_{3}$ solutions with varying amount of lipase. (d) Energy dispersive X-ray fluorescence (ED-XRF) spectra of Ag NPs synthesized from the above mentioned $\mathrm{AgNO}_{3}$ solutions with $100 \mu \mathrm{g} \mathrm{mL} \mathrm{m}^{-1}$ of lipase capping. The $L_{\alpha}$ and $L_{\beta}(1$ and 2 ) lines represent the characteristic electronic transitions from the respective $M$ and $N$ shells to the $L$ shell of $A g$.

subjected FT-IR analyses and the results are shown in Fig. 2. The pristine Ag NPs showed a broad peak at $3437 \mathrm{~cm}^{-1}$ and a small peak at $1632 \mathrm{~cm}^{-1}$, which could be attributed to the hydroxyl and other byproducts such as metaborate, respectively. The pristine lipase, on the other hand, exhibited characteristic stretching peaks in the range of $3200-3500 \mathrm{~cm}^{-1}$ corresponding to hydroxyl and amine groups, two stretching peaks at 2957 and $2872 \mathrm{~cm}^{-1}$ corresponding to $-\mathrm{C}-\mathrm{H}$ functionality and a prominent amide stretching peak at $1661 \mathrm{~cm}^{-1}$ along with some additional stretching peaks in the finger print region. In case of $\mathrm{Ag}$ NPs synthesized in the presence of lipase, the IR spectrum was found to have a good resemblance to that of pristine lipase, which indicates the capping of lipase over the Ag NPs. The gentle shift in the amide stretching peak from $1661 \mathrm{~cm}^{-1}$ to $1651 \mathrm{~cm}^{-1}$ could be attributed to the electrostatic interaction between the surface of Ag NPs and the amide bonds of lipase that additionally confirms the efficient capping of lipase over $\mathrm{Ag}$ NPs. These results are in line with the literature..$^{25}$

The size of the as-synthesized lipase-capped Ag NPs were determined using dynamic light scattering (DLS) and the results are presented in Fig. 3. The DLS analyses revealed that the hydrodynamic size of the nanoparticles possessed significant dependency on the concentration of the capping agent and a lesser dependency on the concentration of $\mathrm{AgNO}_{3}$. When the concentration of $\mathrm{AgNO}_{3}$ was fixed, the particle size was found to

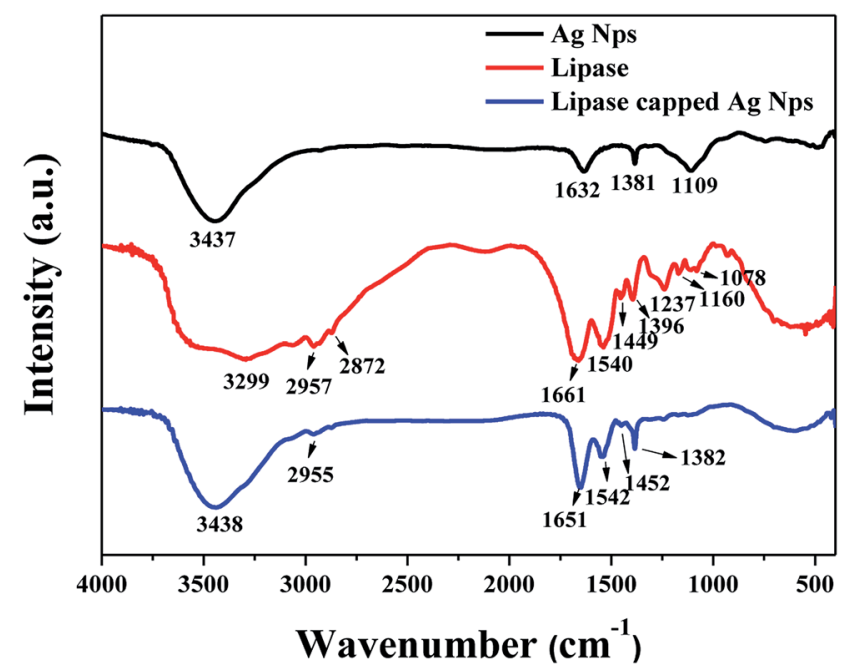

Fig. 2 FT-IR spectra of pristine Ag NPs, pristine lipase and lipasecapped Ag NPs. 

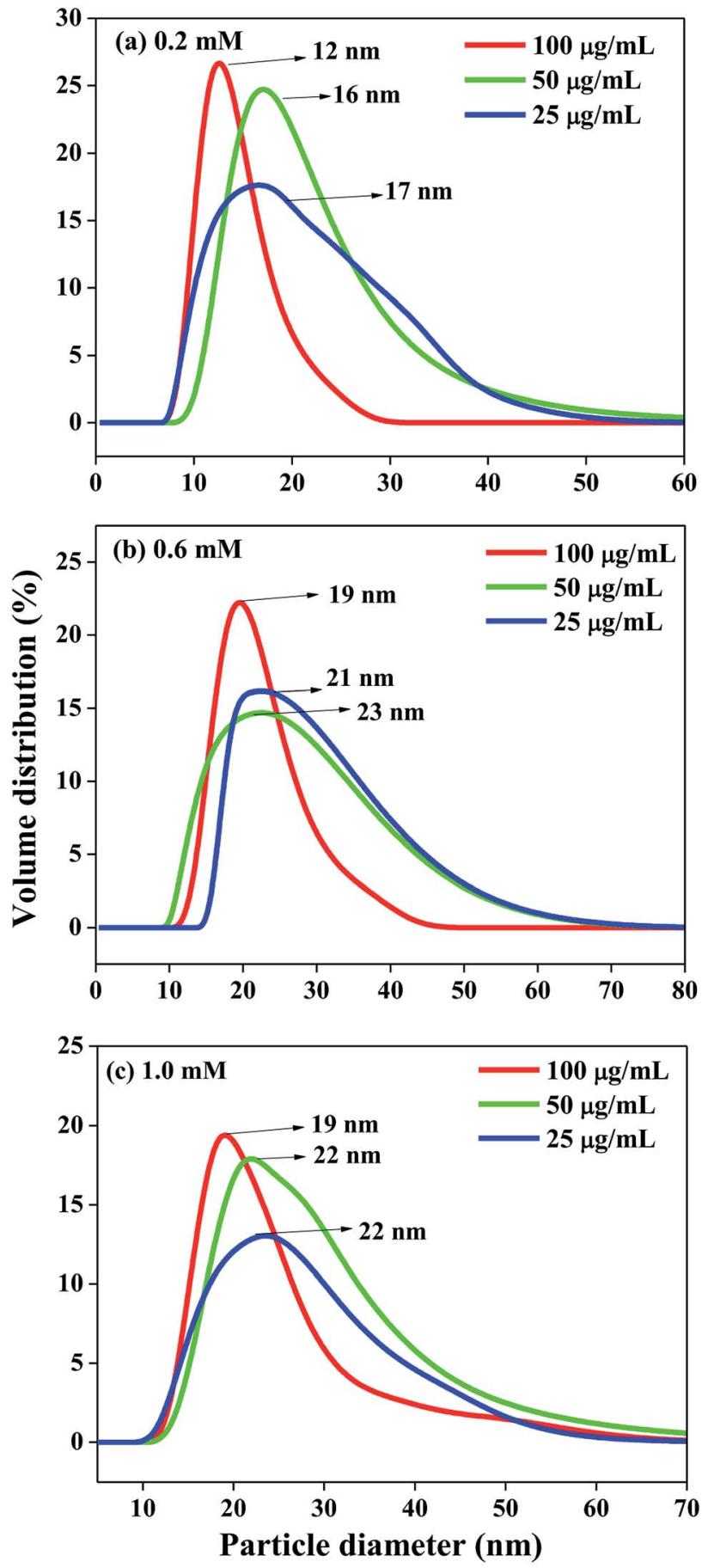

Fig. 3 DLS size distribution of Ag NPs synthesized from (a) $0.2 \mathrm{mM}$, (b) $0.6 \mathrm{mM}$ and (c) $1.0 \mathrm{mM} \mathrm{AgNO}_{3}$ solutions with varying amount of lipase.

decrease with increasing amount of lipase capping agent (25$100 \mu \mathrm{g} \mathrm{mL}^{-1}$ ), indicating the efficient capping by lipase and thus leading to smaller, stable and highly dispersible nanoparticles. When the concentration of $\mathrm{AgNO}_{3}$ was increased from 0.2 to $0.6 \mathrm{mM}$, the particle size was observed to be increased at all concentrations of lipase used. It was noticed that the size of the Ag NPs obtained with 0.6 and $1.0 \mathrm{mM}$ of $\mathrm{AgNO}_{3}$ was very comparable with equivalent amount of lipase capping agent. These results corroborate the observation from UV-Vis spectroscopy studies. Thus, the smallest AgNPs among the lot was observed to be obtained with $0.2 \mathrm{mM}$ of $\mathrm{AgNO}_{3}$ capped with $100 \mu \mathrm{g} \mathrm{mL} \mathrm{L}^{-1}$ of lipase. It was generally observed that at higher concentrations of $\mathrm{AgNO}_{3}$ and lower concentrations of lipase the sizes as well as the polydispersity of the obtained Ag NPs were increased.

HR-TEM imaging was performed over selected samples in order to understand the effect of lipase capping on the size and morphology of the Ag NPs and the results are presented in Fig. 4(a-j). The Ag NPs synthesized from $0.2 \mathrm{mM} \mathrm{AgNO}_{3}$ solution with varying lipase concentration and the nanoparticles synthesized from varying initial $\mathrm{AgNO}_{3}$ concentrations capped with a fixed lipase concentration of $100 \mu \mathrm{g} \mathrm{mL}{ }^{-1}$ were chosen for the analysis. As can be seen from the figure, almost all the nanoparticles were found to be nearly spherical in shape. When the $\mathrm{AgNO}_{3}$ concentration was fixed at $0.2 \mathrm{mM}$, with the increase in lipase capping amount from 25 to $100 \mu \mathrm{g} \mathrm{mL} \mathrm{m}^{-1}$, the average size of the Ag NPs was found to decrease from $\sim 10$ to $5 \mathrm{~nm}$. When the $\mathrm{AgNO}_{3}$ concentration was varied from 0.2 to $1.0 \mathrm{mM}$ with $100 \mu \mathrm{g} \mathrm{mL} \mathrm{m}^{-1}$ capping of lipase, the average size of the $\mathrm{Ag}$ NPs was found to be in the range of $\sim 5$ to $7 \mathrm{~nm}$. Thus, the effect on the size was majorly influenced by the amount of lipase capping, not on the initial $\mathrm{AgNO}_{3}$ concentration used in this study. These observations have clearly shown the efficient capping by lipase at $100 \mu \mathrm{g} \mathrm{mL} \mathrm{L}^{-1}$ and thus further corroborates the DLS analyses.

For studying the antimicrobial activity, the stock solutions of $\mathrm{Ag}$ NPs mentioned earlier were diluted to obtain the final working solutions having silver concentrations of 10, 15, 20, 25 and $30 \mathrm{nM}$ (Fig. 5). Several studies report that Ag NPs work effectively against Gram negative bacteria. Therefore, we initially performed the antibacterial studies against the Gram negative bacteria Pseudomonas putida (Fig. 5(a-e)). Among the controls, pristine lipase and $\mathrm{NaBH}_{4}$ did not exhibit any significant inhibition of the microbial growth, whereas the positive control ampicillin showed $\sim 60 \%$ inhibition. With respect to the stock solution, the working solutions obtained from $0.2 \mathrm{mM}$ solution of Ag NPs exhibited the best antimicrobial activity compared to the remaining two. This could be due to the smaller hydrodynamic size of the nanoparticles, as indicated by DLS analyses, that may have enhanced the permeation of the nanoparticles into the microbial cell. Among the working solutions, the antimicrobial activity of all the samples was found to be enhanced with increasing concentration from 10 to $30 \mathrm{nM}$, which could be attributed to the higher bioavailability of the nanoparticles. It is also observed that the antimicrobial activity was steadily increased with increasing lipase capping in most of the cases. This could be due to the reason that the Ag NPs are highly stabilized and therefore well-dispersible, when capped with higher amount of lipase. With $20 \mathrm{nM}$ and above concentrations, all the Ag NPs were found to exhibit $\geq 50 \%$ bactericidal effect. It is noteworthy that the most efficient MIC was achieved even at $10 \mathrm{nM}$ concentration with Ag NPs obtained from $0.2 \mathrm{mM}$ stock solutions.

We further explored the antibacterial effect of lipase capped Ag NPs against the Gram positive bacteria Staphylococcus aureus (Fig. 5(f-j)). In this case also the lipase capped Ag NPs exhibited 

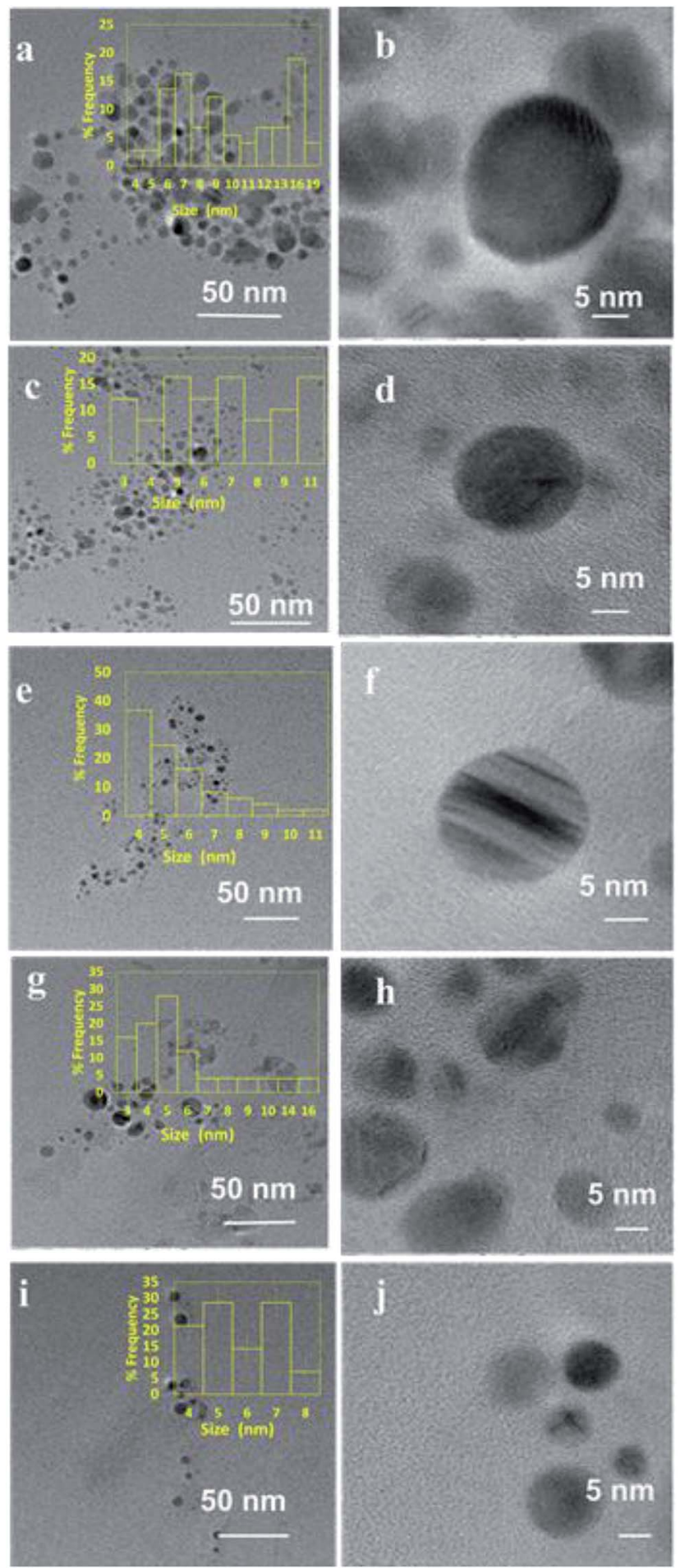

Fig. $4 \mathrm{HR}$ TEM images of Ag NPs synthesized from $0.2 \mathrm{mM} \mathrm{AgNO}$ solution capped with (a and b) 25, (c and d) 50 and (e and f) $100 \mu \mathrm{g}$ $\mathrm{mL}^{-1}$ of lipase. HR-TEM images of Ag NPs synthesized from ( $\mathrm{g}$ and $\mathrm{h}$ ) 0.6 and ( $i$ and j) $1.0 \mathrm{mM} \mathrm{AgNO}_{3}$ solution capped with $100 \mu \mathrm{g} \mathrm{mL}^{-1}$ of lipase capped with $100 \mu \mathrm{g}$ of lipase.

significant bactericidal effect, although the effect is slightly lesser than the Pseudomonas putida. The overall trend in terms of the effect of Ag NPs concentration and the lipase quantity towards bactericidal effect was found to be similar to the
Pseudomonas putida. In this case too, the negative controls such as pristine lipase and $\mathrm{NaBH}_{4}$ did not exhibit any significant bactericidal effect. However, the positive control ampicillin showed $\sim 40 \%$ inhibition, which is significantly lesser than in the case of Gram negative bacteria. It was found that at $30 \mathrm{nM}$ concentration, all the Ag NPs sample solutions exhibited $\geq 50 \%$ antimicrobial activity. Again, the best MIC was achieved at concentration as low as $10 \mathrm{nM}$ with Ag NPs capped with $100 \mu \mathrm{g}$ $\mathrm{mL}^{-1}$ of lipase obtained from $0.2 \mathrm{mM}$ stock solutions.

In order to explore the applicability of probiotic lipase capped AgNPs towards broad spectrum antimicrobial activity, we also studied the effect of the Ag NPs over a fungal strain Aspergillus niger (Fig. 5(k-o)). It is known that the antibiotics are generally less effective against fungal strains and therefore the antifungal drug amphotericin B was chosen as the positive control. This positive control exhibited $\sim 50 \%$ of fungicidal activity, while the negative controls pristine lipase and $\mathrm{NaBH}_{4}$ did not exhibit any significant fungicidal effect. As expected, the required amount of Ag NPs to exhibit significant antifungal effect was found to be higher than that against the bacteria. The lowest concentration of Ag NPs required to exhibit the MIC was found to be at $15 \mathrm{~nm}$ concentration obtained from $0.2 \mathrm{mM}$ stock solution of $\mathrm{Ag}$ NPs capped with $100 \mu \mathrm{g} \mathrm{mL} \mathrm{m}^{-1}$ of lipase. It is noteworthy that $\sim 80 \%$ of fungicidal effect was exhibited by $30 \mathrm{nM}$ solutions obtained from $0.2 \mathrm{mM}$ stock solution of Ag NPs capped with $100 \mu \mathrm{g} \mathrm{mL} \mathrm{m}^{-1}$ of lipase.

The above results clearly demonstrate the high antimicrobial efficacy of the Ag NPs stabilized with the probiotic lipase. Although it is not feasible to directly compare the MIC values reported in literature due to the differences in various influencing factors such as microbial strain, resistance level, initial microbial concentration, variation in the culture media, method adopted to calculate MIC, size/shape of Ag NPs and the stabilizing agent used, but our studies demonstrated the high antimicrobial activity in very low concentrations of Ag NPs much below the $\mathrm{LC}_{50}$ value of zebra fish. ${ }^{10,12,13,21}$ Table $\mathrm{S} 1 \dagger$ shows the comparative MIC values of Ag NPs available in the literature against various microbial strains. ${ }^{35-52}$ As can be seen from the table, majority of the literature reported MIC values of Ag NPs against both bacteria and fungi in the $\mu \mathrm{g} \mathrm{mL}^{-1}$ range. There are only a very few articles reporting the MIC values in the $\mathrm{ng} \mathrm{mL}^{-1}$ range, which are closer to our current findings.

Although plethora of reports exist on the mechanistic studies of the antimicrobial activity of Ag NPs, the precise mechanisms are still unclear, ${ }^{29}$ but the following factors are considered to be the possible reasons for their activity. The Ag NPs are considered to bind initially to the cell membrane, gain entry into the cell and bind to the DNA, thereby believed to cause interference in the replication process. ${ }^{30,31}$ Other theories state the binding of Ag NPs to the -SH group of the enzymes involved in electron transport chain (ETC) resulting in catalytic oxidation of the sulfhydryl group of the ETC proteins of the cell and further inactivating the proteins by forming disulfide linkages. ${ }^{32-34}$ It is known that the surface of Gram negative bacteria consists of lipopolysaccharides in its outer membrane, while the outer membrane of Gram positive bacteria mainly consists of peptidoglycans. Since the proteins are amphoteric in nature that 

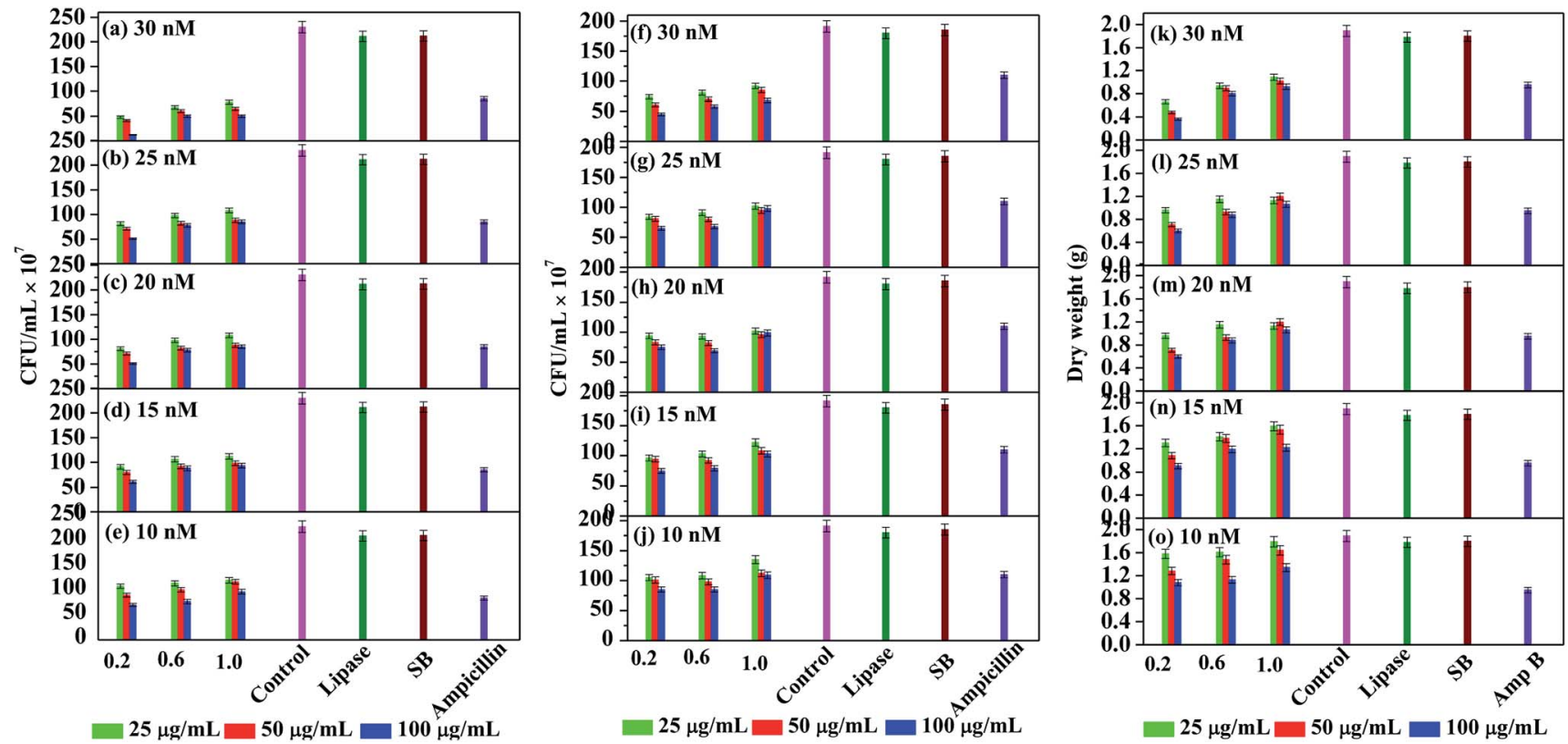

Fig. 5 Antimicrobial activity of Ag NPs against (a-e) P. putida, ( $\mathrm{f}-\mathrm{j}) \mathrm{S}$. aureus and $(\mathrm{k}-\mathrm{O})$ A. niger tested against positive control of ampicillin and amphotericin B (in case of $A$. niger), untreated control and negative controls of lipase treated culture and sodium borohydride (SB).

consist of both acidic and basic moieties, they can bind to a variety of surfaces to facilitate easy penetration of the Ag NPs through the outer membrane of the microbes and thereby initiate the cascade of chemical and biological changes, which could result in the enhanced antimicrobial activity. Thus, our results reveal that the capping of Ag NPs with probiotic lipase demonstrate high potential towards broad spectrum antimicrobial activity at very low concentrations in the range of $\mathrm{ppb}$ (ng $\mathrm{mL}^{-1}$ ).

\section{Conclusion}

Probiotic lipase from Lactobacillus plantarum was employed as a stabilizing agent for Ag NPs synthesized through $\mathrm{NaBH}_{4}$ reduction method. The concentrations of lipase and $\mathrm{AgNO}_{3}$ were systematically varied from $25-100 \mu \mathrm{g} \mathrm{mL}^{-1}$ and $0.2-$ 1.0 $\mathrm{mM}$, respectively. While FT-IR studies revealed the successful capping of lipase over Ag NPs, UV-Vis spectroscopic studies indicated the formation of smaller size nanoparticles with increased lipase concentration. The DLS and HR-TEM analyses revealed that the $\mathrm{Ag}$ NPs obtained from $0.2 \mathrm{mM}$ $\mathrm{AgNO}_{3}$ solution with $100 \mu \mathrm{g} \mathrm{mL} \mathrm{L}^{-1}$ of lipase capping were the smallest in size. Among all the combinations, the $100 \mu \mathrm{g} \mathrm{mL}$ lipase capped Ag NPs synthesized from $0.2 \mathrm{mM} \mathrm{AgNO}_{3}$ solution exhibited the best antimicrobial property against both Gram positive (S. aureus) and Gram negative (P. putida) bacteria at a MIC of $10 \mathrm{nM}$. In case of $A$. niger, the MIC exhibited by the same composition was found to be $15 \mathrm{nM}$. Thus, the combination of ultra-small size Ag NPs and lipase capping resulted in synergistic and efficient antimicrobial activity at concentrations much lower than the $\mathrm{LC}_{50}$ values of zebrafish. Furthermore, the efficient MIC values against the representative bacteria and fungus reveals the high potential of the lipase capped Ag NPs as broad spectrum antimicrobial agents.

\section{Conflicts of interest}

There are no conflicts to declare.

\section{Acknowledgements}

The authors would like to thank BITS Pilani Hyderabad campus for the financial support. The authors also thank the Central Analytical Laboratory of BITS Pilani Hyderabad campus for EDXRF analyses.

\section{References}

1 W.-R. Li, X.-B. Xie, Q.-S. Shi, H.-Y. Zeng, Y.-S. OU-Yang and Y.-B. Chen, Appl. Microbiol. Biotechnol., 2010, 85, 1115-1122. 2 K. Bush, Ann. N. Y. Acad. Sci., 2010, 1213, 1-4.

3 N. Kardos and A. L. Demain, Appl. Microbiol. Biotechnol., 2011, 92, 677-687.

4 C. A. Arias and B. E. Murray, N. Engl. J. Med., 2009, 360, 439443.

5 R. W. Meek, H. Vyas and L. J. V. Piddock, PLoS Biol., 2015, 13, e1002266.

6 L. Sandegren, Upsala J. Med. Sci., 2014, 119, 103-107.

7 D. Carter, A. Charlett, S. Conti, J. V Robotham, A. P. Johnson, D. M. Livermore, T. Fowler, M. Sharland, S. Hopkins, N. Woodford, P. Burgess and S. Dobra, Antibiotics, 2017, 6, 9. 8 B.-H. Mao, Z.-Y. Chen, Y.-J. Wang and S.-J. Yan, Sci. Rep., 2018, 8, 2445.

9 E. I. Westerband and A. L. Hicks, Environ. Sci.: Nano, 2018, 5, 933-945. 
10 M. J. Hajipour, K. M. Fromm, A. Akbar Ashkarran, D. Jimenez de Aberasturi, I. R. de Larramendi, T. Rojo, V. Serpooshan, W. J. Parak and M. Mahmoudi, Trends Biotechnol., 2012, 30, 499-511.

11 T. M. Tolaymat, A. M. El Badawy, A. Genaidy, K. G. Scheckel, T. P. Luxton and M. Suidan, Sci. Total Environ., 2010, 408, 999-1006.

12 B. Ajitha, Y. A. Kumar Reddy, P. S. Reddy, H.-J. Jeon and C. W. Ahn, RSC Adv., 2016, 6, 36171-36179.

13 S. Mohan, O. S. Oluwafemi, S. P. Songca, V. P. Jayachandran, D. Rouxel, O. Joubert, N. Kalarikkal and S. Thomas, J. Mol. Liq., 2016, 213, 75-81.

14 J. Chen, J. Wang, X. Zhang and Y. Jin, Mater. Chem. Phys., 2008, 108, 421-424.

15 A. J. Kora, R. Manjusha and J. Arunachalam, Mater. Sci. Eng., C, 2009, 29, 2104-2109.

16 A. Gebregeorgis, C. Bhan, O. Wilson and D. Raghavan, J. Colloid Interface Sci., 2013, 389, 31-41.

17 V. Gopinath, S. Priyadarshini, N. Meera Priyadharsshini, K. Pandian and P. Velusamy, Mater. Lett., 2013, 91, 224-227.

18 H. Matsumoto, Y. Koyama and A. Tanioka, J. Colloid Interface Sci., 2003, 264, 82-88.

19 R. Sanghi and P. Verma, Bioresour. Technol., 2009, 100, 501504.

20 P. L. Drake and K. J. Hazelwood, Ann. Occup. Hyg., 2005, 49, 575-585.

21 K. Bilberg, M. B. Hovgaard, F. Besenbacher and E. Baatrup, J. Toxicol., 2012, 2012, 293784.

22 L. K. Barker, J. R. Giska, T. S. Radniecki and L. Semprini, Chemosphere, 2018, 206, 606-614.

23 S. R. Uppada, M. Akula, A. Bhattacharya and J. R. Dutta, J. Genet. Eng. Biotechnol., 2017, 15, 331-334.

24 I. Khan, S. K. Vishwakarma, A. A. Khan, G. Ramakrishnan and J. R. Dutta, Clin. Hemorheol. Microcirc., 2018, 69, 197205.

25 I. Khan, R. Nagarjuna, J. Ray Dutta and R. Ganesan, Appl. Nanosci., DOI: 10.1007/s13204-018-0735-7.

26 I. Khan, J. Ray Dutta and R. Ganesan, Int. J. Biol. Macromol., 2017, 95, 126-131.

27 S. Ramyasree and J. R. Dutta, Biocatal. Agric. Biotechnol., 2013, 4, 393-398.

28 K. C. Song, S. M. Lee, T. S. Park and B. S. Lee, Korean J. Chem. Eng., 2009, 26, 153-155.

29 S. Boudebbouze, A. W. Coleman, Y. Tauran, H. Mkaouar, F. Perret, A. Garnier, A. Brioude, B. Kim, E. Maguin and M. Rhimi, Chem. Commun., 2013, 49, 7150.

30 S. Prabhu and E. K. Poulose, Int. Nano Lett., 2012, 2, 32.
31 J. S. Kim, E. Kuk, K. N. Yu, J.-H. Kim, S. J. Park, H. J. Lee, S. H. Kim, Y. K. Park, Y. H. Park, C.-Y. Hwang, Y.-K. Kim, Y.-S. Lee, D. H. Jeong and M.-H. Cho, Nanomedicine, 2007, 3, 95-101.

32 I. Sondi and B. Salopek-Sondi, J. Colloid Interface Sci., 2004, 275, 177-182.

33 B. Reidy, A. Haase, A. Luch, K. Dawson and I. Lynch, Materials, 2013, 6, 2295-2350.

34 C. M. Niemeyer, Angew. Chem., Int. Ed., 2001, 40, 4128-4158. 35 H. M. M. Ibrahim, J. Radiat. Res. Appl. Sci., 2015, 8, 265-275.

36 M. E. Samberg, P. E. Orndorff and N. A. Monteiro-Riviere, Nanotoxicology, 2011, 5, 244-253.

37 A. J. Kora and J. Arunachalam, World J. Microbiol. Biotechnol., 2011, 27, 1209-1216.

38 G. A. Martínez-Castañón, N. Niño-Martínez, F. MartínezGutierrez, J. R. Martínez-Mendoza and F. Ruiz, J. Nanopart. Res., 2008, 10, 1343-1348.

39 R. Krishnan, V. Arumugam and S. K. Vasaviah, J. Nanomed. Nanotechnol., 2015, 6, 1000285.

40 S. Agnihotri, S. Mukherji and S. Mukherji, RSC Adv., 2014, 4, 3974-3983.

41 C.-N. Lok, C.-M. Ho, R. Chen, Q.-Y. He, W.-Y. Yu, H. Sun, P. K.-H. Tam, J.-F. Chiu and C.-M. Che, JBIC, J. Biol. Inorg. Chem., 2007, 12, 527-534.

42 P. Li, J. Li, C. Wu, Q. Wu and J. Li, Nanotechnology, 2005, 16, 1912-1917.

43 Y. Zhou, Y. Kong, S. Kundu, J. D. Cirillo and H. Liang, J. Nanobiotechnol., 2012, 10, 19.

44 N. Supraja, T. N. V. K. V. Prasad, T. G. Krishna and E. David, Appl. Nanosci., 2016, 6, 581-590.

45 S. Senthamilselvi, P. Kumar, A. L. Prabha and M. Govindaraju, Nano Biomed. Eng., 2013, 5, 102-106.

46 A. Martínez-Abad, J. M. Lagarón and M. J. Ocio, Int. J. Food Microbiol., 2014, 174, 39-46.

47 D. M. Eby, N. M. Schaeublin, K. E. Farrington, S. M. Hussain and G. R. Johnson, ACS Nano, 2009, 3, 984-994.

48 S. Nam, B. Park and B. D. Condon, RSC Adv., 2018, 8, 2193721947.

49 K. Thiyagarajan, V. K. Bharti, S. Tyagi, P. K. Tyagi, A. Ahuja, K. Kumar, T. Raj and B. Kumar, $R S C A d v ., 2018$, 8, 2321323229.

50 S. Saha, B. Gupta, K. Gupta and M. G. Chaudhuri, Appl. Nanosci., 2016, 6, 1137-1147.

51 S. Agnihotri, S. Mukherji and S. Mukherji, RSC Adv., 2014, 4, 3974-3983.

52 H. Lu, L. Yu, Q. Liu and J. Du, Polym. Chem., 2013, 4, 3448. 